https://doi.org/10.1007/s11837-021-04930-5

(C) 2021 The Minerals, Metals \& Materials Society

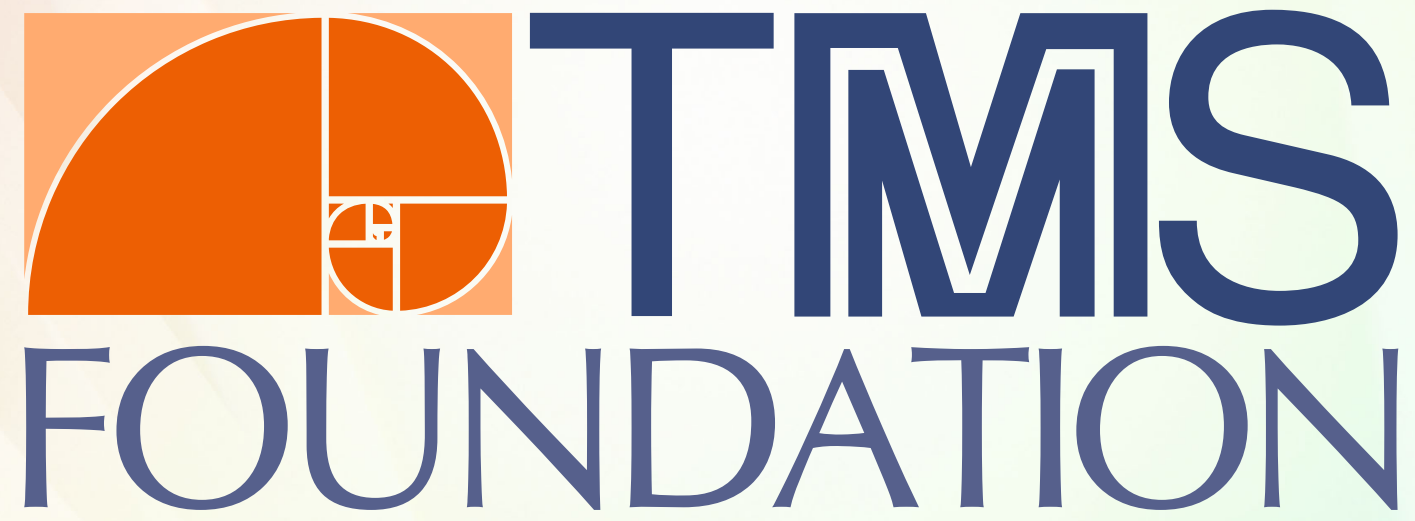

\title{
Committed to a Stronger Futt
The TMS Foundation 2020 Annual Report
}

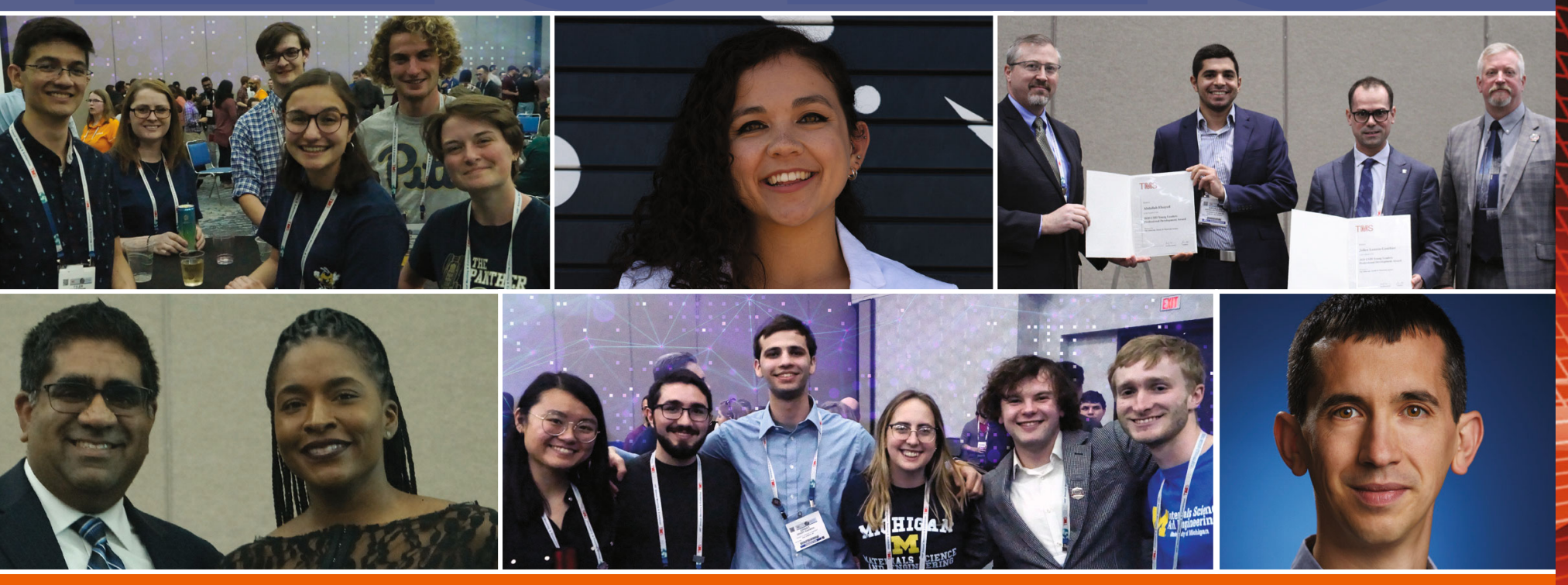


"The deliberate and dedicated support of young professionals in TMS, made possible by both the TMS Foundation and so many engaged, uplifting members, has helped advance my career and has made TMS feel like home. I am excited to continue working within TMS and alongside the Foundation to ensure that our membership will be diverse, vibrant, and dynamic as we tackle the most pressing technological challenges now and into the future."

-Jessica Krogstad, 2020 Early Career Faculty Fellow

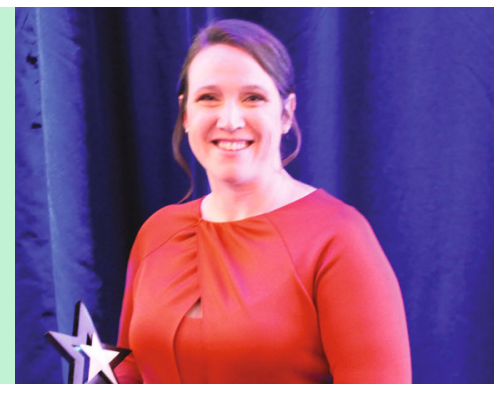

\section{A LETTER FROM}

\section{TMS FOUNDATION LEADERSHIP}

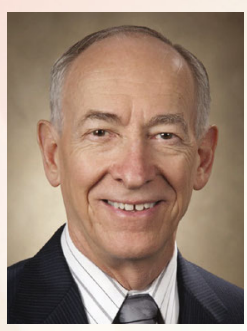

2020 began with the TMS

Foundation Board of Trustees and

TMS Board of Directors meeting to outline a challenge. With renewed commitment to supporting students and early career professionals, the two boards made plans for meeting ambitious philanthropic goals and engaging Society members in pursuit of these goals. Shortly after, the COVID-19 pandemic magnified the importance of this commitment.

What the pandemic demonstrated, was exactly what the Foundation trustees reaffirmed in February. Students and early career professionals faced many unprecedented roadblocks proving that the need to provide for these TMS members in the most vulnerable stages of their careers was greater than ever.

With the support of 292 generous donors, the TMS Foundation did not waver in answering the call to provide financial assistance, valuable recognition, and leadership opportunities. Those 292 donors, 56 of whom made a gift for the first time in 2020, raised a total of $\$ 172,308$. During the 2020 year-end appeal campaign alone, which ran from mid-October through the end of December, a total of $\$ 105,915$ was raised to ensure the strength of our profession now and in the future.

Together, the TMS Foundation and its generous benefactors accomplished a great deal in 2020. When we stand together, we can make a difference in many lives. And we look forward to making an even greater impact in the years to come.

Sincerely,

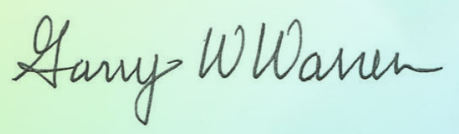

\section{Garry W. Warren}

Chair, TMS Foundation

Board of Trustees

Member, TMS Foundation

Gold Society

\section{FOUNDATION BOARD OF TRUSTEES}

\author{
CHAIR \\ Garry W. Warren \\ University of Alabama
}

\section{EXECUTIVE COMMITTEE REPRESENTATIVE \\ James Foley \\ Los Alamos National Laboratory}

\section{TRUSTEES}

Viola Acoff

University of Alabama

Carl M. Cady

Los Alamos National Laboratory

David DeYoung

Alcoa Technical Center

Hani Henein

University of Alberta

Edward D. Herderick

The Ohio State University

Stanley M. Howard

South Dakota School of Mines \& Technology

Marc A. Meyers

University of California, Santa Barbara

Brajendra Mishra

Metal Processing Institute and Worcester

Polytechnic Institute

Ray Peterson

Real Alloy

David A. Shifler

Office of Naval Research

Robert D. Shull

National Institute of Standards and Technology

SECRETARY

James J. Robinson

TMS Executive Director 


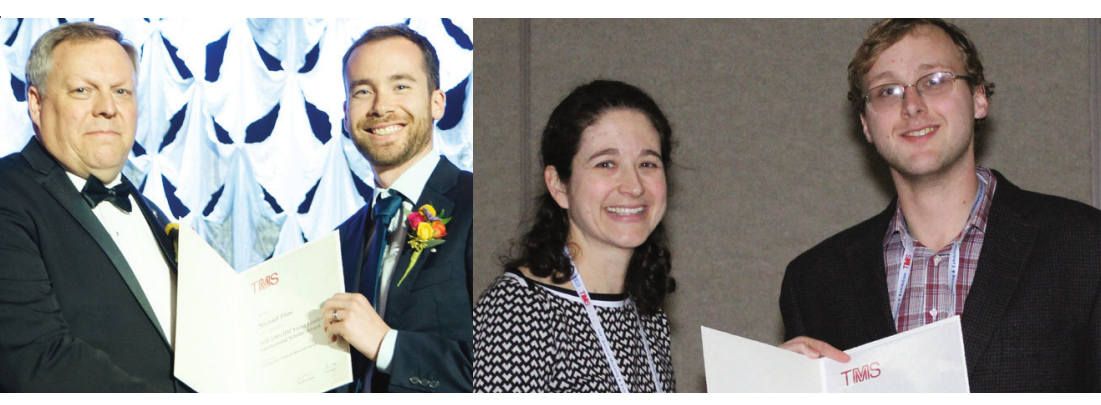

\section{OUR MISSION}

The TMS Foundation supports students and young professionals with meaningful financial assistance and impactful career-building experiences. To learn more about the mission, vision, and history of the TMS Foundation, visit the About section at www.TMSFoundation.org.

\section{OUR PROGRAMS}

\section{STUDENTS}

By supporting scholarships, travel grants, and educational enrichment programs for students, the TMS Foundation helps remove barriers to education while encouraging a deeper involvement in the greater materials community.

\section{EARLY CAREER PROFESSIONALS}

The TMS Foundation offers professional recognition awards, opportunities for presenting work and developing symposia, and leadership development programs through its support for professionals at this key stage in their career development.

\section{ESTABLISHED PROFESSIONALS}

Awards supported by the TMS Foundation encourage diversity within the professions, outstanding mentors or educators, and distinguished achievements, helping to boost prestige within the fields.

\section{OUTREACH INITIATIVES}

The TMS Foundation also supports the Materials Explorers $^{\mathrm{TM}}$ high school outreach program and the TMS Bladesmithing Competition for college students, as well as student participation in the Electronic Materials Conference and the ASM Materials Camps.

\section{TMS FOUNDATION 2020 FINANCIAL OVERVIEW}

The financial information below provides two perspectives on the TMS Foundation's performance in 2020:

- Donations, inclusive of new endowments being established

- Program expenditures, including all gifts issued through the Foundation

\section{TMS FOUNDATION GIVING}

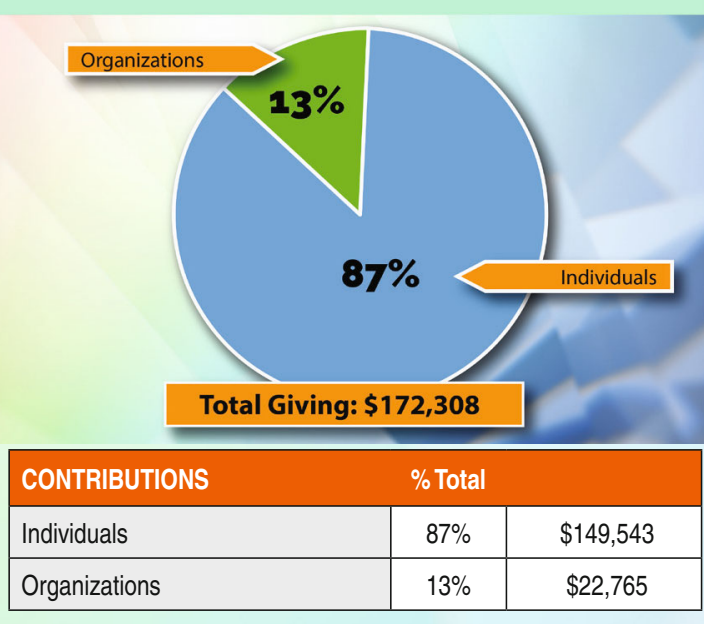

\section{TMS FOUNDATION} PROGRAM EXPENDITURES

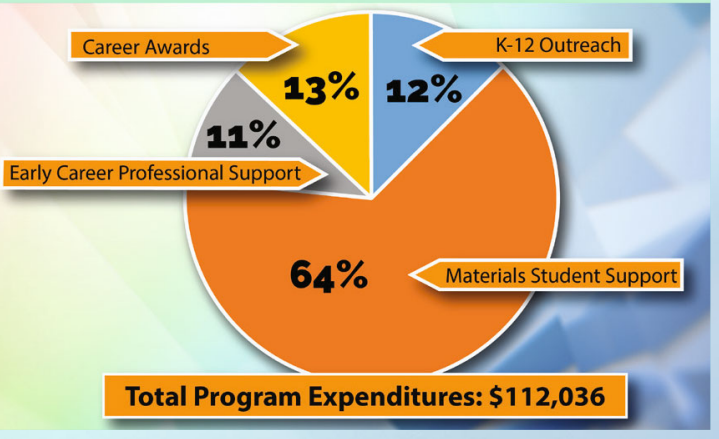

\begin{tabular}{|l|c|c|}
\hline PROGRAM EXPENDITURES & $\%$ Total \\
\hline Materials Student Support & $64 \%$ & $\$ 71,936$ \\
\hline Career Awards & $13 \%$ & $\$ 14,477$ \\
\hline K-12 Outreach & $12 \%$ & $\$ 13,810$ \\
\hline Early Career Professional Support & $11 \%$ & $\$ 11,813$ \\
\hline
\end{tabular}




\section{THANK YOU TO OUR 2020 DONORS}

In addition to special donor groups such as the $\mathbf{4 0 / 4 0}$ Club for young professionals and the $\mathbf{1 8 7 1}$ Legacy Circle for individuals who have provided for the TMS Foundation through planned giving, the TMS Foundation celebrates its donors through its Lifetime Giving Honorific Societies and the Annual Giving Honor Roll. With their generous contributions to the TMS Foundation, our donors are making a significant and permanent impact on the future of the minerals, metals, and materials professions.

To view current members of both honor rolls, visit wWw.TMSFoundation.org/HonorRolls.

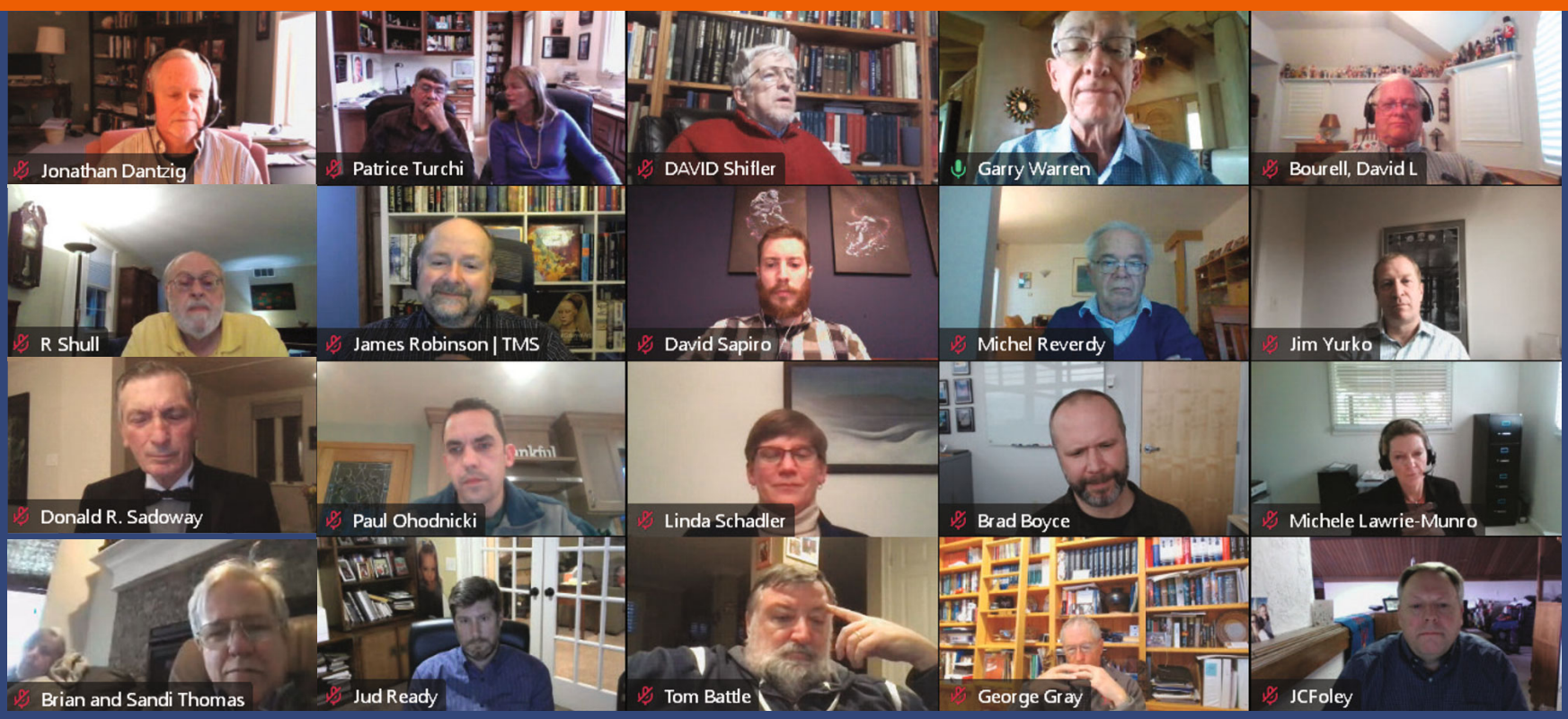

"You who are gathered here this evening are not only resilient in your own lives, but you also reached out to others in need in their lives with your financial generosity," said Garry Warren (fourth photo, top row) to the attendees of the Foundation's March 2021 donor appreciation, held virtually for the first time. "Although the world changed, the need did not. The TMS Foundation and its many beneficiaries are deeply grateful to you."

-Garry Warren, at the 2020 Virtual Donor Appreciation Dinner

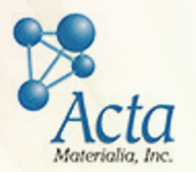

Acta Materialia Inc.

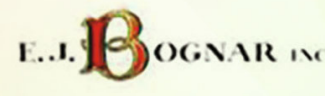

Bognar and Company Inc.

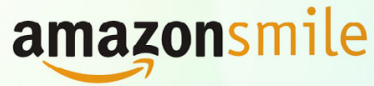

AmazonSmile

Foundation

\section{CHARLES \& ESTHER LEE KIMERLING CHARITABLE FOUNDATION}

Charles \& Esther Lee Kimerling Charitable Foundation

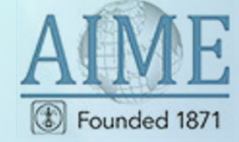

American Institute of Mining Metallurgical and Petroleum Engineers (AIME)

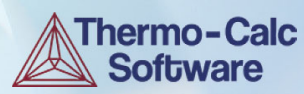

Thermo-Calc Software Inc. (U.S.)

You can make a difference, too, by donating to the TMS Foundation online or mailing a check, payable to the TMS Foundation, to the address below.

wwww.TMSFoundation.org 1-724-776-9000

TMSFoundation@tms.org
TMS Foundation

5700 Corporate Drive Suite 750 Pittsburgh, PA 15237

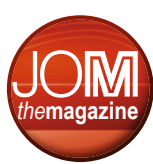

